\title{
Modelo de geração de viagens de carga em áreas urbanas: um estudo para bares, restaurantes e supermercados
}

\author{
Leise Kelli de Oliveira ${ }^{1}$, Renata Lúcia Magalhães de Oliveira ${ }^{2}$, Cláudia Márcia de Fátima Ramos ${ }^{3}$ e Daniel \\ Gonçalves Ebias ${ }^{4}$
}

\begin{abstract}
Resumo: A distribuição urbana de mercadorias impulsiona o desenvolvimento econômico, apesar dos impactos negativos relacionados à atividade. Para mitigar tais problemas, modelos de geração de viagens de carga podem ser uma estratégica para conhecer o comportamento do fluxo de mercadorias no meio urbano e desenvolver políticas públicas efetivas. Nesse contexto, este artigo apresenta modelos de geração de viagens de carga para Bares, Restaurantes, Mercados e Supermercados em Belo Horizonte. Uma pesquisa de campo foi conduzida para obtenção dos dados, que foram analisados para determinar a correlação entre as variáveis que descrevem a geração de viagens, cujos resultados indicam que a área do estabelecimento comercial explica a geração de viagens de carga na área de estudo. A comparação com modelos existentes indicou semelhanças e divergências, destacando a necessidade de modelos locais. Os resultados foram analisados espacialmente e indicaram a importância da localização destes fenômenos no espaço para a definição de políticas públicas.
\end{abstract}

Palavras-chave: transporte urbano de mercadorias; modelos de geração de viagens de carga; planejamento de transporte.

Abstract: Urban freight transportation stimulates economic development, despite its inherent operational urban conflicts. An effective way to mitigate those negative effects is to propose adequate public policy. Therefore, freight trip generation models can be used to analyze the cargo flow in urban space. In this context, this paper intends to propose models for bars, restaurants, grocery stores and supermarkets in Belo Horizonte. Hence, a field research was conducted, followed by the correlation analysis considering the variables that best describe the freight trip generation phenomenon. The results indicate that area of establishment explains effectively the demand for freight movement in the study area. Besides that, the models were compared with those acquired in the literature review and this comparison reinforced the need of local models. The results were also analyzed spatially, outstanding the importance of the location these phenomena regarding the definition of public policies.

Keywords: urban freight transport; freight trip generation model; transport planning.

\section{INTRODUÇÃO}

As atividades sociais e econômicas desenvolvidas em áreas urbanas tornam necessária a movimentação de pessoas e mercadorias. As pessoas necessitam de bens e serviços que são oferecidos pelas atividades comerciais e que devem estar disponíveis no tempo e nos locais desejados. A indisponibilidade desses bens pode, de certa forma, alterar de maneira significativa as rotinas urbanas provocando um desequilíbrio nas relações sociais e econômicas existentes (Melo, 2002). Neste contexto, o transporte de mercadorias sustenta as áreas urbanas, estando relacionado ao crescimento e ao desempenho dos setores econômicos de uma cidade. As áreas urbanas necessitam ser continuamente abastecidas por bens demandados pelas pessoas e, para isso, é necessário um sistema de distribuição urbana de mercadorias confiável e eficiente.

Devido à relevância econômica da distribuição urbana de mercadorias e aos impactos que a mesma causa no

\footnotetext{
1 Leise Kelli de Oliveira, Departamento de Engenharia de Transportes e Geotecnia, UFMG. (leise@etg.ufmg.br)

2 Renata Lúcia Magalhães de Oliveira, Departamento de Engenharia, CEFET-MG. (renataoliveira@deii.cefetmg.br)

${ }^{3}$ Cláudia Márcia de Fátima Ramos, Departamento de Engenharia de

Transportes e Geotecnia, UFMG. (claudiamfr@terra.com.br)

${ }^{4}$ Daniel Gonçalves Ebias, Departamento de Engenharia, UNIFOR-MG.

(daniel_ebias@hotmail.com)
}

Manuscrito recebido em 11/01/2016 e aprovado para publicação em 28/07/2016

Este artigo é parte de TRANSPORTES v. 24, n. 2, 2016. ISSN: 2237-1346 (online). DOI:10.4237/transportes.v24i2.1058 sistema viário e no meio ambiente, nas últimas décadas, verificou-se a necessidade de estudar esta problemática. Neste ensejo, surgiu o conceito de logística urbana na busca de soluções para a melhoria do transporte urbano de mercadorias, promovendo suporte ao desenvolvimento sustentável das cidades (Taniguchi et al., 2001; Dutra, 2004; Prata et al., 2012; Gonzalez-Feliu et al., 2014, Oliveira, 2014). Atualmente, a logística urbana pode ser considerada uma nova área no planejamento do transporte urbano.

Um aspecto importante da distribuição urbana de mercadorias é a geração de viagens de carga, que, de forma concentrada, ocorre em locais denominados Polos Geradores de Viagens de Carga (PGV Carga). A distribuição urbana de mercadorias gera um complexo fluxo de veículos de carga, necessitando ser objeto de estudo no intuito de minimizar os impactos (congestionamentos, poluição atmosférica, sonora, saturação da infraestrutura viária, dentre outros) aos envolvidos (Dablanc, 2007, Gasparini et al. 2010, Rodrigue, 2013, Cui et al., 2015). Para a minimização desses impactos, os principais polos que geram fluxos de carga devem ser identificados e os tipos de viagens produzidas e atraídas pelas atividades desenvolvidas em uma cidade devem ser analisados para subsidiar políticas públicas eficientes (Comi et al., 2012). Para tanto, estudos e a utilização de modelagem matemática são importantes para um melhor planejamento urbano.

Quando um empreendimento tem potencial de produzir e atrair viagens de veículos de carga, os impactos causados por ele no sistema viário são diferenciados e relacionam-se ao seu porte e à região em que se encontra instalado, sendo mais expressivos quando localizados em áreas urbanas. Assim, a identificação dos fluxos de veículos de carga 
gerados é também de grande importância para o gerenciamento da mobilidade da região do entorno desses empreendimentos (Campos et al., 2012).

Tendo em vista a necessidade de realizar estudos relacionados à geração de viagens de empreendimentos caracterizados como PGV Carga, este artigo tem por objetivo analisar as viagens de veículos de carga atraídas por bares, restaurantes, mercados e supermercados em Belo Horizonte, visando entender o impacto das viagens de carga destes setores no tráfego urbano. Este escopo deve-se ao fato de alimentos e bebidas serem os principais produtos entregues na região central de Belo Horizonte (Oliveira, 2014). Ainda, segundo Souza et al. (2010) e Campos et al. (2012), o desenvolvimento de modelos de geração de viagens de carga é um campo a ser explorado no Brasil devido ao baixo número de estudos, além da necessidade de modelos compatíveis com as particularidades locais (Grieco e Portugal, 2010).

Para apresentar a importância, metodologia e os resultados, este artigo tem a seguinte estrutura: na seção 2 apresenta-se o conceito de polos geradores de viagens, os estudos desenvolvidos no contexto brasileiro e a importância da modelagem da geração de viagens. Na seção 3 é detalhada a metodologia utilizada para o desenvolvimento dos modelos e análises. Os resultados e uma análise comparativa dos modelos estão apresentados na seção 4, que apresenta uma subseção de discussão dos resultados. Na seção 5 finaliza-se este artigo com as considerações finais.

\section{POLOS GERADORES DE VIAGENS DE CARGA E A MODELAGEM DA GERAÇÃO DE VIAGENS}

Segundo Gonçalves et al. (2012), algumas atividades têm um poder de atratividade capaz de impactar os componentes do espaço como as pessoas e os veículos. Assim, para Portugal (2012), o conceito de PGV considera os deslocamentos realizados por veículos motorizados individuais como automóveis e motocicletas, além das viagens que estão relacionadas à maior produtividade social, como as viagens não motorizadas, as viagens por transporte público e aquelas que movimentam carga.

Segundo Campos et al. (2012), os PGVs Carga são definidos como 'empreendimentos com potencial de produzir e atrair viagens de veículos de carga, como caminhões, camionetas, caminhonetes e furgões. O impacto desses empreendimentos no sistema viário e quanto ao uso e ocupação do solo é diferenciado, dependendo da região e do porte do empreendimento, porém tendem a ser mais expressivos em áreas urbanas, onde já se verifica trânsito intenso de veículos motorizados e adensamento populacional' (Campos et al., 2012, p. 539).

Por motivo de escopo e considerando que os modelos de geração de viagens de carga devem ser compatíveis com as necessidades locais, este artigo explora apenas a literatura brasileira, com destaque para os estudos de Marra (1999), Melo (2002), Silva e Waisman (2007) e Gasparini et al., (2010). Holguín-Veras et al. (2011) afirmam que a lacuna na literatura de modelos apropriados pode ser explicada, em parte, pela falta de conhecimento do sistema (não é possível desenvolver bons modelos se o sistema não é compreendido), de modelos (ter dados não significa que você tem conhecimento, sendo necessárias teorias para explicar o comportamento do sistema) e de dados (a coleta de dados é mais efetiva quando se tem conhecimento do sistema e dos requisitos dos modelos desenvolvidos).

Marra (1999) estudou a movimentação urbana de cargas com o objetivo de identificar padrões de demanda por mercadorias em áreas residenciais e comerciais em Campinas (São Paulo). Para determinar a demanda mensal por mercadorias, foi realizada pesquisa de campo e os dados da demanda domiciliar foram relacionados com indicadores socioeconômicos da população, tais como: (i) o nível de renda nos bairros; (ii) o número de moradores/empregados; e (iii) a área do imóvel. A pesquisa apontou os tipos de uso do solo que causam maior geração de demanda por carga, as principais mercadorias em circulação e os veículos de carga mais utilizados.

Melo (2002) avaliou a demanda pelo transporte de carga em função do movimento de mercadorias e de viagens de veículos de carga na cidade do Rio de Janeiro. Foi utilizada pesquisa de campo para obtenção dos dados para a análise. A primeira etapa da pesquisa foi realizada em empresas produtoras e/ou transportadoras para identificar a quantidade de carga produzida e movimentada e os respectivos destinos, a partir de uma amostra estabelecida, considerando a produção e a movimentação semanal ou mensal. A segunda etapa ocorreu em estabelecimentos comerciais visando identificar a quantidade de carga recebida, a partir de uma amostra estabelecida, por semana ou mês. As áreas escolhidas para a pesquisa foram aquelas onde empreendimentos como escolas, hipermercados, centros empresariais, indústrias, condomínios residenciais, terminais de transporte de carga e de passageiros, shopping centers e outros provocam diversos deslocamentos de pessoas e/ou mercadorias. Como resultado do trabalho, foi utilizada a modelagem de regressão para verificar a correlação existente entre as taxas de viagens (variável dependente) e as variáveis características de cada estabelecimento ou empresa. A autora analisou os segmentos de supermercados, vestuário, comércio varejista, bares e restaurantes, material de construção e combustível. Como desdobramento da pesquisa de Melo (2002), Campos e Melo (2004) apresentaram modelos de atração e geração de viagens de carga para a cidade do Rio de Janeiro, correlacionando o número de viagens com o número de veículos da empresa e o número médio de entregas no roteiro.

Silva e Waisman (2007) determinaram modelo de geração de viagens de caminhões em bares e restaurantes no bairro da Mooca, em São Paulo. As informações sobre o comportamento das viagens e a caracterização do uso do solo foram coletadas por meio de pesquisa de campo em trinta estabelecimentos comerciais. Os dados permitiram verificar que, de um modo geral, a variável dependente quantidade média semanal de viagens de caminhões é função das variáveis independentes: área do estabelecimento $\left(\mathrm{em} \mathrm{m}^{2}\right)$ e número de funcionários. Os autores ressaltam que os resultados obtidos se restringem à região e ao tipo de atividade/uso de solo estudado.

Gasparini et al. (2010) tiveram como foco principal o volume de viagens de veículos de carga para shopping centers e supermercados no Rio de Janeiro. As pesquisas indicaram que sexta-feira é o dia da semana com maior volume de viagens e que o caminhão é o tipo de veículo que 
mais atende aos empreendimentos. Na modelagem da demanda foi utilizado o método de regressão linear e as melhores equações encontradas no estudo dos shopping centers tiveram como variáveis independentes a área construída, a área bruta locável e o volume médio de clientes/dia.

Para os supermercados, as melhores equações obtidas consideraram a área de vendas, as vagas de estacionamento, o volume médio de clientes/dia e o número de funcionários como variáveis independentes. Detalhes podem ser obtidos em Gasparini (2008).

Mais recentemente, as referências nacionais envolvendo PGVs Carga focaram o impacto ambiental (Guimarães et al., 2014; Oliveira et al., 2014; D'Agosto et al., 2014). Na Tabela 1 apresenta-se o resumo dos modelos brasileiros, por meio da qual é possível perceber a concentração dos modelos no Rio de Janeiro e São Paulo, principalmente baseados em viagens de carga, com predomínio da variável dependente área construída e número de funcionários.

Em relação à abordagem metodológica, Souza et al. (2010) utilizaram os trabalhos nacionais e 21 internacionais para analisar o perfil dos modelos de geração de viagens de carga. Os autores identificaram a predominância de modelos de regressão linear simples ou múltipla nas referências nacionais e ressaltaram que 'a adequada escolha de uma variável independente pode contribuir mais para um bom resultado do modelo do que o uso de modelos excessivamente elaborados ou que utilizam muitas variáveis independentes' (Souza et al., 2010, p. 56).

Holguín-Veras et al. (2012) identificaram os seguintes fatores no desenvolvimento e análise dos modelos: (i) variáveis dependentes: viagens-veículo (vehicle-trip-based), mercadoria (commodity-based) e valor; (ii) variáveis independentes: emprego, área, uso do solo, dados econômicos (como vendas, segmento da indústria, tipo de comércio), tipo de veículo e tipo de mercadoria; (iii) nível de agregação: desagregado ou agregado; (iv) nível geográfico: metropolitano, estadual, nacional, corredores de transporte e facilidades logísticas (como portos); (v) abordagem metodológica: taxas de viagens, regressão linear, regressão espacial, análise de variância, série temporal, análise de inputoutput e redes neurais; e, (vi) estrutura do modelo: linear ou não linear. Kulpa (2014) identificou os mesmos fatores em revisão mais recente da literatura.

Além disso, Holguín-Veras et al. (2012) destacaram que, dos modelos revisados, $47 \%$ são baseados em viagens, $48 \%$ dos modelos são desagregados e $49 \%$ utilizam o emprego como variável independente ( $9 \%$ utilizam a área). Em relação à técnica de modelagem, $25 \%$ utilizam a regressão linear e $10 \%$ utilizam taxas. Os modelos que utilizam taxas, em geral, consideram como variável explicativa o número de empregados ou a área do empreendimento, muitas vezes desenvolvidos sem testar a significância das variáveis utilizadas ou a validade da função (Holguín-Veras et al., 2011). Para Holguín-Veras et al. (2011), o uso de taxas subestima o número de viagens geradas por pequenos empreendimentos e superestima para grandes empreendimentos. Neste caso, é importante definir intervalos de validade da taxa de geração de viagens, restringindo o intervalo de validade do modelo, visando melhorar a precisão do modelo e evitando sub e/ou super estimativas.

Para Comi et al. (2012), a modelagem da demanda do transporte de carga deve ser adotada no processo de de- cisão envolvendo o planejamento de transporte e o gerenciamento de tráfego. Para tanto, os modelos devem ser baseados na (i) viagem, (ii) mercadoria, (iii) entrega ou (iv) mistos. Os modelos baseados em veículos (truck-based) têm como unidade de referência o número de veículos de carga e permitem estimar o número de veículos de carga atraídos e/ou gerados por uma zona, cuja distribuição espacial permite obter os fluxos de carga (matriz origem-destino, O-D). Esta abordagem tem como vantagem a facilidade de obtenção de dados para calibração e validação da matriz O-D. Além disso, Comi et al. (2012) ressaltaram que este tipo de abordagem é específica para a área em que o modelo é concebido e existem sérias falhas na transferência para outros contextos urbanos.

Os modelos baseados em mercadorias (commoditybased) consideram a quantidade de mercadorias como unidade de referência e permitem estimar a matriz origem-destino através de uma sequência de modelos que consideram a atração, aquisição e quantidade de veículos. Os modelos baseados na entrega (delivery-based) utilizam a entrega como unidade de referência, o que permite relacionar geradores e operadores de transporte por meio de uma mesma unidade de referência (entregas) e utilizam uma sequência de modelos de estatística descritiva para analisar o fenômeno (Comi et al., 2012).

As diferentes abordagens para a modelagem da demanda de carga indicam que a escolha do modelo (baseado no veículo, mercadoria, entrega ou mistos) depende da disponibilidade dos dados e da aplicação do modelo (Kulpa, 2014). Mesmos os modelos mais sofisticados podem não fornecer bons resultados se os dados de entrada não são confiáveis (Kulpa, 2014). Desta forma, o escopo, a abordagem metodológica e a fonte de dados são elementos importantes no processo de modelagem da demanda (Comi et al., 2012).

\section{METODOLOGIA}

As 'ferramentas que auxiliem na identificação dos volumes de viagens de veículos de carga produzidos e atraídos pelos PGVs de Carga podem ser consideradas instrumentos de valor para o gerenciamento da mobilidade' (Souza et al., 2010, pg. 57). Considerando a importância da estimativa do número de viagens de veículos de carga para identificação do impacto da atividade no tráfego urbano, este estudo adaptou a proposta de Campos et al. (2012) para elaboração de modelos de geração de viagens de carga, resultando nas seguintes etapas e, respectivas atividades:

- Etapa 1: definição do objetivo, escopo e horizonte de tempo;

- Etapa 2: definição das variáveis dependentes e independentes;

- Etapa 3: identificação dos empreendimentos na área de estudo:

○ Identificação dos setores utilizando Classificação Nacional de Atividades Econômicas (CNAE);

- Geocodificação e a representação espacial da localização dos estabelecimentos para os segmentos de interesse do estudo; 
OLIVEIRA, L.K.; OLIVEIRA, R.L.M.; RAMOS, M.L.A.; EBIAS, D.G.

Tabela 1. Síntese dos modelos de geração de viagens de carga em âmbito nacional.

\begin{tabular}{|c|c|c|c|c|c|c|c|c|c|}
\hline Referência & Local & $\begin{array}{l}\text { Tipo de } \\
\text { Modelo } \\
\end{array}$ & $\begin{array}{c}\text { Variável } \\
\text { Dependente }\end{array}$ & Variáveis Independentes & Setor & Equação & $\mathbf{R}^{2}$ & Domínio & Amostra \\
\hline \multirow{3}{*}{ Marra (1999) } & \multirow{3}{*}{$\begin{array}{l}\text { Campinas } \\
\quad(\mathrm{SP})\end{array}$} & \multirow{3}{*}{$\begin{array}{l}\text { Baseado em } \\
\text { mercadoria }\end{array}$} & \multirow{3}{*}{$\begin{array}{l}\text { Total de carga } \\
\text { no período }\end{array}$} & Área construída & \multirow{3}{*}{ Não especificado } & $y=21,828 x-2530,3$ & 0,90 & $94 \mathrm{~m}^{2} \leq \mathrm{x} \leq 853$ & \multirow{3}{*}{400} \\
\hline & & & & Número de funcionários & & $y=648,14 x-1556,5$ & 0,93 & $4 \leq x \leq 29$ & \\
\hline & & & & $\begin{array}{c}\text { Rendimento médio } \\
\text { (per capita) }\end{array}$ & & $\mathrm{y}=8,1221 \mathrm{e}^{0,5766 \mathrm{x}}$ & 0,88 & $5,5 \leq \mathrm{x} \leq 11,9$ & \\
\hline \multirow{6}{*}{ Melo (2002) } & \multirow{6}{*}{$\begin{array}{c}\text { Rio de } \\
\text { Janeiro (RJ) }\end{array}$} & \multirow{6}{*}{$\begin{array}{l}\text { Baseado em } \\
\text { viagens }\end{array}$} & \multirow{6}{*}{$\begin{array}{l}\text { Número de } \\
\text { viagens }\end{array}$} & \multirow{6}{*}{ Área Construída } & Supermercado & $\mathrm{y}=1,1522+0,012 \mathrm{x}$ & 0,56 & - & 13 \\
\hline & & & & & Vestuário & $y=1,7499-0,0003 x$ & 0,01 & - & 17 \\
\hline & & & & & Comércio Varejista & $y=0,9260+0,0010 x$ & 0,88 & - & 8 \\
\hline & & & & & Bar e restaurante & $y=1,3334+0,0019 x$ & 0,80 & - & 12 \\
\hline & & & & & $\begin{array}{l}\text { Material de Cons- } \\
\text { trução }\end{array}$ & $y=0,0035+0,0046 x$ & 0,58 & - & 10 \\
\hline & & & & & Combustível & $y=0,4858+0,000038 x$ & 0,33 & - & 18 \\
\hline \multirow{3}{*}{$\begin{array}{l}\text { Campos e Melo } \\
\text { (2004) }\end{array}$} & \multirow{3}{*}{$\begin{array}{c}\text { Rio de } \\
\text { Janeiro (RJ) }\end{array}$} & \multirow{3}{*}{$\begin{array}{l}\text { Baseado em } \\
\text { viagens }\end{array}$} & \multirow{3}{*}{$\begin{array}{l}\text { Número de via- } \\
\text { gens realizadas } \\
\text { pela empresa } \\
\text { de transporte }\end{array}$} & $\begin{array}{l}\text { Número de viagens por } \\
\text { caminhão }\end{array}$ & $\begin{array}{c}\text { Supermercado, } \\
\text { comércio varejista, } \\
\text { bar, restaurante e } \\
\text { material de } \\
\text { construção } \\
\end{array}$ & $y=1,11+0,0012 x$ & 0,60 & - & 43 \\
\hline & & & & $\begin{array}{l}\text { Número de veículos da } \\
\text { empresa de transporte }\end{array}$ & \multirow{2}{*}{ Não especificado } & $\mathrm{y}=18,766+0,931 \mathrm{x}$ & 0,88 & \multirow[b]{2}{*}{ - } & 20 \\
\hline & & & & $\begin{array}{c}\text { Número médio de } \\
\text { estabelecimentos visitados }\end{array}$ & & $y=28,21+0,04199 x$ & 0,7 & & 20 \\
\hline \multirow{3}{*}{$\begin{array}{l}\text { Silva e Wais- } \\
\text { man } \\
(2007)\end{array}$} & \multirow{3}{*}{$\begin{array}{l}\text { São Paulo } \\
\quad \text { (SP) }\end{array}$} & \multirow{3}{*}{$\begin{array}{l}\text { Baseado em } \\
\text { Viagens }\end{array}$} & \multirow{3}{*}{$\begin{array}{l}\text { Número de } \\
\text { viagens }\end{array}$} & Área do Estabelecimento & \multirow{3}{*}{ Bar e Restaurante } & $y=2,9634+0,0446 x$ & 0,71 & $60 \mathrm{~m}^{2} \leq \mathrm{x} \leq 500 \mathrm{~m}^{2}$ & \multirow{3}{*}{30} \\
\hline & & & & Número de Funcionários & & $y=1,9719+1,4590 x$ & 0,74 & $2 \leq \mathrm{x} \leq 17$ & \\
\hline & & & & $\begin{array}{l}\text { Área do Estabelecimento } \\
\left(\mathrm{x}_{1}\right) \text { e Número de } \\
\text { Funcionários }\left(\mathrm{x}_{2}\right) \\
\end{array}$ & & $\begin{array}{c}\mathrm{y}=2,0742+0,0167 \mathrm{x}_{1}+0,9670 \mathrm{x}_{2} \\
\mathrm{y}=-5,67+0,0755 \mathrm{x}_{1}+1,8372 \mathrm{x}_{2} \\
-0,0050560 \mathrm{x}^{1} \mathrm{x}^{2}\end{array}$ & $\begin{array}{l}0,75 \\
0,91 \\
\end{array}$ & $\begin{array}{c}60 \mathrm{~m}^{2} \leq \mathrm{x}_{1} \leq 500 \mathrm{~m}^{2} \\
2 \leq \mathrm{x}_{2} \leq 17\end{array}$ & \\
\hline \multirow{2}{*}{$\begin{array}{l}\text { Gasparini } \\
(2008)\end{array}$} & \multirow{2}{*}{$\begin{array}{l}\text { Rio de } \\
\text { Janeiro } \\
(\mathrm{RJ})\end{array}$} & \multirow{2}{*}{$\begin{array}{l}\text { Baseado em } \\
\text { Viagens }\end{array}$} & $\begin{array}{c}\text { Volume de } \\
\text { veículos no dia } \\
\text { pico } \\
\end{array}$ & $\begin{array}{c}\text { Vagas de Estacionamento } \\
\left(\mathrm{x}_{1}\right) \text { e Número de Funcio- } \\
\text { nários }\left(\mathrm{x}_{2}\right)\end{array}$ & Supermercados & $\mathrm{y}=2,63+0,00172 \mathrm{x}_{1}+0,00867 \mathrm{x}_{2}$ & 0,52 & $\begin{array}{l}12 \leq \mathrm{x}_{1} \leq 380 \\
80 \leq \mathrm{x}_{2} \leq 246\end{array}$ & 7 \\
\hline & & & $\begin{array}{l}\text { Volume de } \\
\text { veículos no dia } \\
\text { pico }\end{array}$ & $\begin{array}{l}\text { Área construída }(\mathrm{x} 1) \mathrm{e} \\
\text { volume médio de clientes } \\
(\mathrm{x} 2)\end{array}$ & Shopping Center & $\mathrm{y}=0,0014 \mathrm{x}_{1}+0,00063 \mathrm{x}_{2}$ & 0,98 & $\begin{array}{l}12 \leq \mathrm{x}_{1} \leq 380 \\
80 \leq \mathrm{x}_{2} \leq 246\end{array}$ & 7 \\
\hline
\end{tabular}


- Etapa 4: obtenção de dados:

o Série histórica: obtida por meio de documentos públicos e/ou cedidos pela administração dos empreendimentos; coleta de dados, amostra, período de coleta de dados e informações necessárias

- Etapa 5: caracterização dos empreendimentos analisados:

o Caracterização do porte, localização, número de funcionários, periodicidade do abastecimento, dentre outras informações relevantes para compreensão do problema em estudo;

o Análise do padrão de atração/produção de viagens de carga;

o Identificação de períodos de sazonalidades, tendências.

- Etapa 6: análise da correlação entre os dados

○ Verificação da correlação das variáveis utilizadas no estudo.

- Etapa 7: desenvolvimento de modelos de geração de carga:

○ Utilização de regressão linear como abordagem metodológica;

○ Avaliação da acurácia do modelo, considerando o coeficiente de explicação $\left(\mathrm{R}^{2}\right)$ e o teste-t;

o Representação espacial dos resultados do modelo mais ajustado para geração/atração de cada conjunto de dados considerando os empreendimentos da área de estudo.

- Etapa 8: verificação do modelo através dos modelos desenvolvidos na etapa 7. A verificação deve ser realizada para o maior número possível de empreendimentos selecionados e utilizados no modelo de geração de viagens de carga;

- Caso os modelos desenvolvidos não sejam validados, retornar à Etapa 3.

- Etapa 9: análise de cluster

o Identificação de clusters da geração de viagens a partir do modelo de regressão proposto para o planejamento do transporte de carga urbana.

O procedimento metodológico para as etapas 1 a 8 encontra-se detalhado em Campos et al. (2012). Este estudo contribui com a inserção da etapa de análise espacial da localização dos empreendimentos e dos resultados obtidos com o modelo de geração de viagens de carga, no intuito de prover instrumentos para definição de políticas públicas para o transporte urbano de mercadorias que considerem as diferenciações espaciais inerentes à complexa ocupação urbana. Para tanto, a localização dos empreendimentos no contexto urbano pode ser analisada considerando a densidade de um fenômeno no espaço, o que permite avaliar a sua concentração sobre a área de interesse.

Com os modelos de geração de viagens de cargas desenvolvidos, utilizou-se a análise de cluster para identificar possíveis padrões espaciais destas viagens com sua localização no meio urbano (Rogerson, 2012). Neste estudo, utilizou-se a análise de cluster Anselin Local Moran's I, que mensura a autocorrelação espacial por meio de uma matriz de pesos, comparando um conjunto de similaridades locacionais com um conjunto de similaridades de atributos (no o Coleta de dados: necessário definir instrumento de

- Comparação dos dados reais com os dados obtidos

caso em estudo, a localização versus a geração de viagens de veículos de carga). Por meio desta técnica são identificados clusters de valores elevados para os atributos (HH), clusters de valores baixos para os atributos (LL), outlier em que um valor alto é cercado por valores baixos (HL) e $\mathrm{ou}$ tlier em que um valor baixo é cercado por valores altos (HL). Estes agrupamentos são representados em mapas de clusters. Assim, ainda como resultado deste artigo, para identificar possíveis localidades no município de Belo Horizonte com concentração de estabelecimentos comerciais com elevada geração de viagens de veículos de carga, foi realizada a análise Anselin Local Moran's I considerando o número de viagens de cargas geradas pelos modelos propostos para cada categoria de estabelecimentos comerciais.

\section{APLICACCÃO DO PROCEDIMENTO METODOLÓGICO}

Este estudo foi desenvolvido para Belo Horizonte, um dos principais centros urbanos brasileiros com uma população estimada de 2,5 milhões de habitantes (IBGE, 2015), distribuídos por $331 \mathrm{~km}^{2}$ e densidade de demográfica de 7.167 hab. $/ \mathrm{km}^{2}$. Belo Horizonte responde por $14,5 \%$ do Produto Interno Bruto (PIB) de Minas Gerais e 1,33\% do PIB do Brasil e ocupa, dessa forma, a quinta posição no ranking dos municípios brasileiros, segundo o valor do PIB Municipal. Belo Horizonte é dividida em nove regionais administrativas, cujas localizações estão indicadas na Figura 1 e respectivas características como área, população e densidade populacional estão apresentadas na Tabela 2.

As subseções seguintes detalham a aplicação do procedimento metodológico descrito na seção anterior.

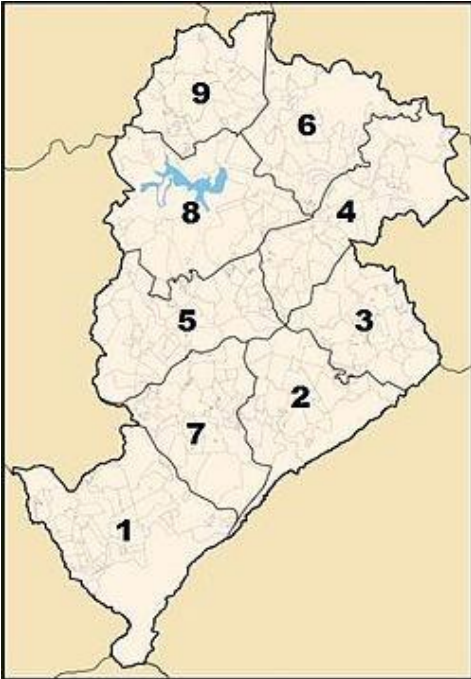

Figura 1. Localização das regionais administrativas.

Tabela 2. Características das regionais administrativas de Belo Horizonte

\begin{tabular}{llccc}
\hline & Regional & População & $\begin{array}{c}\text { Superfície } \\
\left(\mathbf{k m}^{2}\right)\end{array}$ & $\begin{array}{c}\text { Densidade } \\
\left(\mathbf{p o p} / \mathbf{k m}^{\mathbf{2}}\right)\end{array}$ \\
\hline 1 & Barreiro & 282.552 & 53,46 & 5.285 \\
2 & Centro-Sul & 283.776 & 31,73 & 8.943 \\
3 & Leste & 238.539 & 27,902 & 8.5500 \\
4 & Nordeste & 290.535 & 39,33 & 7.382 \\
5 & Noroeste & 268.038 & 30,08 & 8.912 \\
6 & Norte & 212.055 & 31,56 & 6.513 \\
7 & Oeste & 308.549 & 35.93 & 8.587 \\
8 & Pampulha & 226.110 & 21,04 & 4.430 \\
9 & Venda Nova & 265.179 & 29,16 & 9.03 \\
\hline & \multicolumn{5}{c}{ Belo Horizonte, 2015a. } \\
\hline
\end{tabular}

TRANSPORTES, v. 23, n. 3 (2015), p. 53-67 


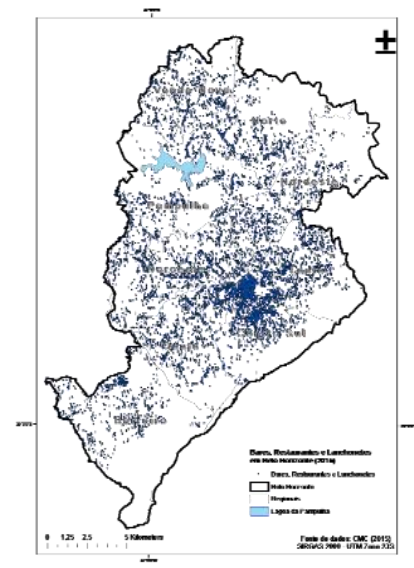

(a) Bares, restaurantes e lanchonetes

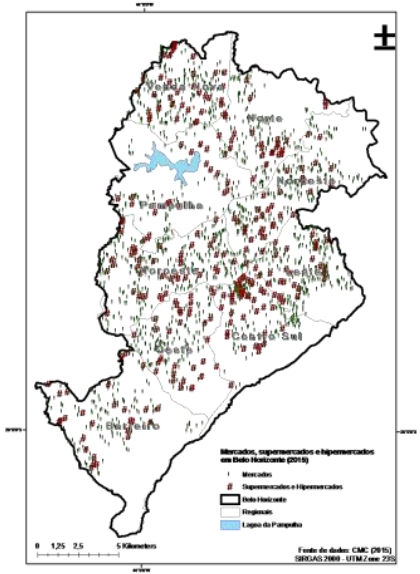

(b) Mercados, supermercados e hipermercados

Figura 2. Localização espacial dos estabelecimentos em Belo Horizonte.

\subsection{Etapa 1: Definição de objetivo, escopo e horizonte de tempo}

Os modelos desenvolvidos neste estudo podem ser utilizados como instrumento para subsidiar o planejamento urbano do transporte carga, conforme proposto por Comi et al. (2012). Para tanto, tem-se como objetivo estimar a geração de viagens de veículos de carga para bares, restaurantes, mercados e supermercados em Belo Horizonte, selecionados devido ao fato de alimentos e bebidas representarem, respectivamente, $29 \%$ e $13 \%$ do volume de mercadoria circulante na região central de Belo Horizonte (Oliveira, 2014). Em função da abrangência municipal, espera-se determinar o número diário de viagens de veículos de carga para o dia pico na região analisada. Como o estudo tem finalidade de planejamento do transporte urbano de carga em Belo Horizonte, o horizonte de tempo é determinado pelas características da região.

Neste estudo não foram considerados atributos referentes à sazonalidade do transporte de carga. Entende-se que existe uma importância significativa da sazonalidade na movimentação de cargas urbanas, em função essencialmente do comportamento da demanda. Entretanto, o impacto dos fluxos de veículos de cargas em determinados períodos do ano é amenizado pela redução do fluxo de viagens em transporte individual no contexto urbano. Como exemplo, tem-se o aumento do consumo em varejo supermercadista no período de férias escolares e uma redução das viagens em veículos particulares por motivo escola e trabalho neste período, equilibrando o uso do sistema viário e reduzindo o impacto da sazonalidade no transporte urbano de mercadorias. Outro aspecto importante para o presente estudo é o horizonte de planejamento. Neste estudo, consideram-se aspectos relacionados ao planejamento estratégico da movimentação de cargas urbanas, para o qual o impacto da sazonalidade é também menor.

\subsection{Etapa 2: Definição das variáveis dependentes e independentes}

Este estudo considera uma abordagem baseada no veículo (truck-based). Assim, a variável dependente (a unidade de referência) é o número de veículos de carga atraído pelo empreendimento. $\mathrm{O}$ número de funcionários e a área de cada estabelecimento são avaliadas como variáveis independentes.

\subsection{Etapa 3: Identificação dos empreendimentos na área de estudo}

Para identificação de empreendimentos, utilizou-se o Cadastro Municipal de Contribuintes de Tributos Mobiliários (Belo Horizonte, 2015), que consiste em um banco de dados pertencente à Prefeitura, com informações sobre as pessoas jurídicas que exercem atividades no município e estão sujeitas ao pagamento de impostos e taxas. Para a identificação destes estabelecimentos, utilizou-se a Classificação Nacional de Atividades Econômicas (CNAE):

- Bares: CNAE 5611202;

- Lanchonetes e bares sem serviço completo: CNAE 5611203;

- Restaurantes: CNAE 5611201;

- Mercados: CNAE 4712100;

- Mercados: CNAE 4712100;

- Supermercados: CNAE 4711302;

- Hipermercados: CNAE 4711301.

Neste estudo, considerou-se a classificação proposta por ITE (2008), para definição de mercados (área inferior a $2.000 \mathrm{~m}^{2}$ ), supermercados (área entre 2.000 e $12.000 \mathrm{~m}^{2}$ ) e hipermercados (área superior a $12.000 \mathrm{~m}^{2}$ ). Em Belo Horizonte existem 259.973 estabelecimentos comerciais, sendo que 14.005 correspondem a bares, lanchonetes e restaurantes e 2.500 correspondem a mercados, supermercados e hipermercados (Belo Horizonte, 2015), cuja localização foi geocodificada e a localização está representada espacialmente na Figura 2.

A Figura 2 permite observar concentração de bares e restaurantes na região Centro-Sul e uma distribuição uniforme de mercados e supermercados em Belo Horizonte, com pequena concentração na área norte da região CentroSul. Este retrato indica a importância de considerar a geração de viagens de carga e o impacto da movimentação dos veículos de carga na infraestrutura viária urbana.

\subsection{Etapa 4: Obtenção de dados}

Para a obtenção de dados, utilizou-se pesquisa de campo com auxílio de um questionário. As entrevistas foram conduzidas com um funcionário do setor administrativo com conhecimento das operações de recebimento de 
Tabela 3. Resumo das informações solicitadas aos entrevistados.

\begin{tabular}{l|l}
\hline Informações do Empreendimento & $\begin{array}{l}\text { nome e endereço do empreendimento; } \\
\text { nome e função do entrevistado; } \\
\text { telefone de contato e e-mail. }\end{array}$ \\
\hline \multirow{2}{*}{ Características do Empreendimento } & $\begin{array}{l}\text { tempo de funcionamento; } \\
\text { dias e horários de funcionamento; } \\
\text { áreas dos empreendimentos; } \\
\text { número de funcionários; } \\
\text { número de caixas ( checkouts), para supermercados. }\end{array}$ \\
\hline Recebimento de Mercadorias & $\begin{array}{l}\text { número de docas; } \\
\text { vagas externas regulamentadas na via; } \\
\text { tipos de mercadoria mais recebidas; } \\
\text { tipos de veículos de carga atraídos; } \\
\text { número médio de veículos de carga recebidos por dia da semana; } \\
\text { horário das entregas; } \\
\text { tempo de descarga; } \\
\text { problemas verificados na operação. }\end{array}$ \\
\hline
\end{tabular}

Tabela 4. Quantidade e representatividade da amostra pesquisada.

\begin{tabular}{ccccc}
\hline Regional & $\begin{array}{c}\text { Bares, Lanchonetes e } \\
\text { Restaurantes }\end{array}$ & $\begin{array}{c}\text { Amostra } \\
(\boldsymbol{\%})\end{array}$ & $\begin{array}{c}\text { Mercados e } \\
\text { Supermercados }\end{array}$ & $\begin{array}{c}\text { Amostra } \\
(\boldsymbol{\%})\end{array}$ \\
\hline Barreiro & - & - & 3 & $7,69 \%$ \\
Centro-Sul & 228 & $20,63 \%$ & 6 & 15,26 \\
Leste & 38 & $23,31 \%$ & 4 & $10,26 \%$ \\
Norte & - & - & 6 & $15,38 \%$ \\
Nordeste & - & - & 4 & $10,26 \%$ \\
Noroeste & - & - & 5 & $12,82 \%$ \\
Oeste & 34 & $36,17 \%$ & 3 & $7,69 \%$ \\
Pampulha & - & - & 3 & $7,69 \%$ \\
Venda Nova & - & - & 5 & $12,82 \%$ \\
Total & 300 & $100 \%$ & 39 & $100 \%$ \\
\hline
\end{tabular}

mercadorias. Na Tabela 3 são apresentadas as principais informações solicitadas durante a entrevista, com foco nas características do empreendimento e no recebimento de mercadorias.

Para definição da amostra, considerou-se como premissa que a demanda por transporte de carga urbana constitui um reflexo direto da localização da atividade (Gasparini, 2008). Neste contexto, foram considerados os requisitos definidos pelo ITE (2008), que recomenda que devam ser pesquisados, no mínimo, três a cinco estabelecimentos para a obtenção das taxas médias de geração de viagens e, ainda, que os estabelecimentos pesquisados devam ter, no mínimo, dois anos de existência. A amostra pesquisada é apresentada na Tabela 4, considerando as regionais administrativas. As regionais com maior concentração de empreendimentos e maior densidade populacional foram contemplados na pesquisa de bares, lanchonetes e restaurantes, buscando alcançar uma amostra maior de empreendimentos. No caso de mercados e supermercados, considerou-se o número mínimo de estabelecimentos, por regional.

Importante destacar que nenhum estabelecimento da classe de hipermercado disponibilizou-se a participar da pesquisa, restringindo os resultados a mercados e supermercados.

\subsection{Etapa 5: Caracterização dos empreendimentos analisados}

A pesquisa de campo permitiu identificar que $68 \%$ dos bares, lanchonetes e restaurantes funcionam durante $o$ dia e a noite, $26 \%$ funciona durante o dia e $6 \%$ apenas a noite. Em relação ao dia de funcionamento, $36 \%$ funcionam diariamente, $46 \%$ dos estabelecimentos funcionam de segunda-feira a sábado, $9 \%$ funcionam de segunda-feira a sexta-feira e os outros $9 \%$ em dias alternados com terça- feira a domingo (4\%), terça-feira a sábado (2\%), quartafeira a domingo (2\%) e quarta-feira a sábado (1\%). Em relação aos mercados e supermercados, a pesquisa de campo permitiu identificar que $84,6 \%$ dos estabelecimentos pesquisados funcionam de segunda-feira a domingo, entre $7 \mathrm{~h}$ e 22 horas, exceto aos domingos, em que 56\% dos supermercados pesquisados encerram suas atividades até às 14 horas.

Em relação às características dos empreendimentos, a área dos bares, lanchonetes e restaurantes que compõe a amostra varia entre $45 \mathrm{~m}^{2}$ e $400 \mathrm{~m}^{2}$, sendo que $39,6 \%$ dos estabelecimentos têm entre $61 \mathrm{~m}^{2}$ a $100 \mathrm{~m}^{2}$. Para mercados, a área varia entre $102 \mathrm{~m}^{2}$ e $1.900 \mathrm{~m}^{2}$ e a área dos supermercados varia entre $2.307 \mathrm{~m}^{2}$ e $6.623 \mathrm{~m}^{2}$.

A infraestrutura para checkouts dos mercados e supermercados pesquisados varia entre 2 e 15 , conforme Tabela 5 com predominância de entre 6 a 8 checkouts em $38,46 \%$ dos empreendimentos e 10 checkouts em 12,82\% dos estabelecimentos pesquisados.

Tabela 5. Número de Checkouts.

\begin{tabular}{ccc}
\hline $\begin{array}{c}\text { Número } \\
\text { de Checkouts }\end{array}$ & Quantidade & Representatividade (\%) \\
\hline 2 & 1 & $2,56 \%$ \\
3 & 4 & $10,25 \%$ \\
4 & 1 & $2,56 \%$ \\
5 & 1 & $2,56 \%$ \\
6 & 5 & $12,82 \%$ \\
7 & 5 & $12,82 \%$ \\
8 & 5 & $12,82 \%$ \\
9 & 2 & $5,12 \%$ \\
10 & 5 & $12,82 \%$ \\
11 & 1 & $2,56 \%$ \\
12 & 4 & $10,25 \%$ \\
13 & 2 & $5,12 \%$ \\
14 & 1 & $2,56 \%$ \\
15 & 1 & $2,56 \%$ \\
\hline
\end{tabular}


Na Tabela 6 é apresentado o número de funcionários dos estabelecimentos pesquisados: em bares, lanchonetes e restaurantes predominam entre 3 e 25 funcionários $(63 \%$ dos estabelecimentos) e em mercados e supermercados predominam de 52 a 75 funcionários $(34,2 \%)$.

Tabela 6. Representatividade do número de funcionários nos empreendimentos.

\begin{tabular}{ccc}
\hline $\begin{array}{c}\text { Número de } \\
\text { Funcionários }\end{array}$ & $\begin{array}{c}\text { Percentual de Bares, } \\
\text { Lanchonete e } \\
\text { Restaurantes }\end{array}$ & $\begin{array}{c}\text { Percentual } \\
\text { de Mercados } \\
\text { e Supermercados }\end{array}$ \\
\hline $\begin{array}{c}\text { Menos de 3 } \\
\text { funcionários }\end{array}$ & $33,4 \%$ & - \\
\hline $\begin{array}{c}\text { De 3 a 25 } \\
\text { funcionários }\end{array}$ & $63 \%$ & $15,8 \%$ \\
\hline $\begin{array}{c}\text { De 30 a 41 } \\
\text { funcionários }\end{array}$ & $3,6 \%$ & $13,2 \%$ \\
\hline $\begin{array}{c}\text { De 52 a 75 } \\
\text { funcionários }\end{array}$ & - & $34,2 \%$ \\
\hline $\begin{array}{c}\text { De 78 a 94 } \\
\text { funcionários }\end{array}$ & - & $23,7 \%$ \\
\hline $\begin{array}{c}\text { De 110 a 210 } \\
\text { funcionários }\end{array}$ & - & $13,2 \%$ \\
\hline
\end{tabular}

Em relação ao recebimento de mercadorias, $3 \%$ dos bares, lanchonetes e restaurantes recebem mercadoria diariamente, $31 \%$ recebe quatro vezes por semana e $41 \%$ recebe cinco vezes por semana. Em relação aos mercados e supermercados, $41 \%$ informaram ocorrer aumento no número de entregas semanais de mercadorias em meses de férias escolares (julho, dezembro e janeiro). Em bares, lanchonetes e restaurantes, a terça-feira é o dia de maior recebimento de mercadorias (30\%), seguido pela sexta-feira $(23 \%)$ e ocorrendo entrega no sábado e domingo. Em mercados e supermercados, sexta-feira é o dia de maior recebimento de mercadorias, correspondendo a $31 \%$ das viagens de veículos de carga atraídas durante a semana, seguidas pela segundafeira $(20 \%)$ e quinta-feira (19\%). Estas informações estão detalhadas na Tabela 7 .

Em relação ao horário das entregas em bares, lanchonetes e restaurantes, $71 \%$ das entregas ocorre entre $8 \mathrm{~h}$ e $10 \mathrm{~h}$, $6 \%$ entre $10 \mathrm{~h}$ e $12 \mathrm{~h}, 7 \%$ entre $14 \mathrm{~h}$ e $18 \mathrm{~h}$ e $16 \%$ não têm horário. Em mercados e supermercados, 66,7\% têm programação para o recebimento das mercadorias, que pode ocorrer em 9h-11h (39,8\%), 11h-14h (22,9\%), 14h-16h (30,1\%) e $16 \mathrm{~h}-19 \mathrm{~h}(6 \%)$. Em 1,2\% dos estabelecimentos, a entrega ocorre entre $6 \mathrm{~h}-8 \mathrm{~h}$ (fora-pico).

Tabela 7. Percentual de viagens de carga atraídas por dia da semana.

\begin{tabular}{ccc}
\hline Dia da Semana & $\begin{array}{c}\text { Bares, } \\
\text { Lanchonetes e } \\
\text { Restaurantes }\end{array}$ & $\begin{array}{c}\text { Mercados e } \\
\text { Supermercados }\end{array}$ \\
\hline Segunda-feira & $6 \%$ & $20 \%$ \\
Terça-feira & $30 \%$ & $12 \%$ \\
Quarta-feira & $15 \%$ & $18 \%$ \\
Quinta-feira & $19 \%$ & $19 \%$ \\
Sexta-feira & $23 \%$ & $31 \%$ \\
Sábado & $4 \%$ & - \\
Domingo & $3 \%$ & - \\
\hline
\end{tabular}

Considerando a infraestrutura para a carga/descarga de mercadorias, apenas $1 \%$ dos bares, lanchonetes e restaurantes possui área de carga e descarga internalizada no empreendimento e 59\% possuem área de carga e descarga regulamentada pela Prefeitura na frente do estabelecimento. Em $40 \%$ dos bares, lanchonetes e restaurantes, a operação de carga e descarga ocorre na rua, em frente ao estabelecimento. Em mercados e supermercados, $33,3 \%$ não possuem área interna destinada ao estacionamento de veículos de carga. Dos mercados e supermercados que possuem área interna, $88,5 \%$ dispõem de docas para o recebimento das mercadorias (possuir área interna não implica em possuir a doca). Além disso, 66,7\% dos mercados e supermercados possuem áreas disponíveis na via pública destinadas às operações de carga e descarga, sendo dispostas em frente à edificação $(53,8 \%)$, situadas na mesma rua $(26,9 \%)$ ou no quarteirão em que se encontra inserido o estabelecimento $(19,2 \%)$

O tempo médio de carga e descarga varia de 10 a 120 minutos, com uma média de 45,9 minutos em mercados e supermercados. Em 56,4\% destes estabelecimentos o tempo de descarga é inferior a 30 minutos e em 15,4\% dos estabelecimentos o tempo de descarga pode chegar até 120 minutos (Tabela 8). Bares, lanchonetes e restaurantes não souberam precisar o tempo desta operação por informar que não acompanham a operação (apenas fazem a conferência da mercadoria).

Tabela 8. Tempo de operação de descarga de mercadorias em mercados e supermercados.

\begin{tabular}{cc}
\hline $\begin{array}{c}\text { Tempo de Operação de Descarga } \\
\text { (em minutos) }\end{array}$ & Percentual \\
\hline 10 & $12,8 \%$ \\
15 & $5,1 \%$ \\
20 & $12,8 \%$ \\
25 & $2,6 \%$ \\
30 & $23,1 \%$ \\
40 & $12,8 \%$ \\
45 & $2,6 \%$ \\
50 & $2,6 \%$ \\
60 & $5,1 \%$ \\
90 & $5,1 \%$ \\
120 & $15,4 \%$ \\
\hline
\end{tabular}

\subsection{Etapa 6: Análise da correlação entre os dados}

A correlação estatística entre o número de viagens de veículos de carga, área e número de funcionários para os setores analisados foi realizada, utilizando o Coeficiente de Correlação de Person, cujos resultados são:

- Bares, lanchonetes e restaurantes:

○ Área e número de viagens de veículos de carga, $\rho$ $=0,74$;

○ Número de funcionários e o de viagens de veículos de carga, $\rho=0,70$.

- Para mercados e supermercados:

○ Área e número de viagens de veículos de carga, $\rho$ $=0,85$;

○ Número de funcionários e o de viagens de veículos de carga, $\rho=0,48$.

Os resultados indicam que todas as variáveis analisadas têm correlação positiva forte, exceto entre as variáveis número de funcionários e viagens de veículos de carga em mercados e supermercados que tem correlação positiva fraca. Estes dados são confirmados pela análise do diagrama de dispersão apresentados na Figura 3, em que a Figura 3(d) indica o baixo coeficiente de explicação (R2) para a relação número de viagens e área do estabelecimento. 


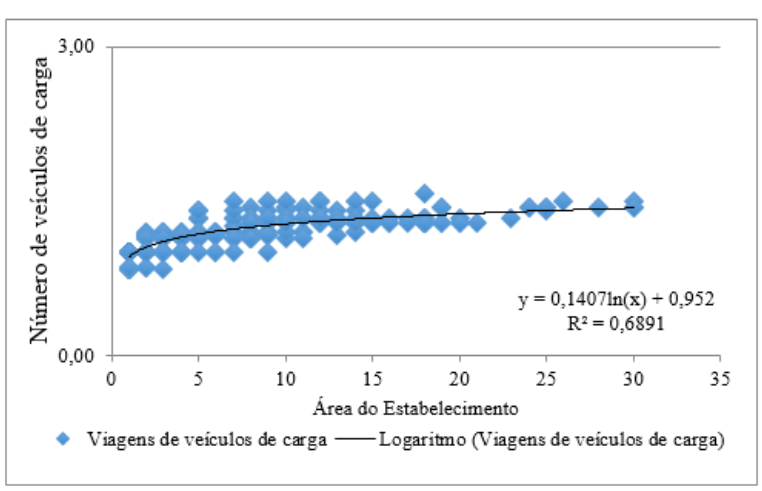

(a) Área e número de viagens de carga para bares, lanchonetes e restaurantes

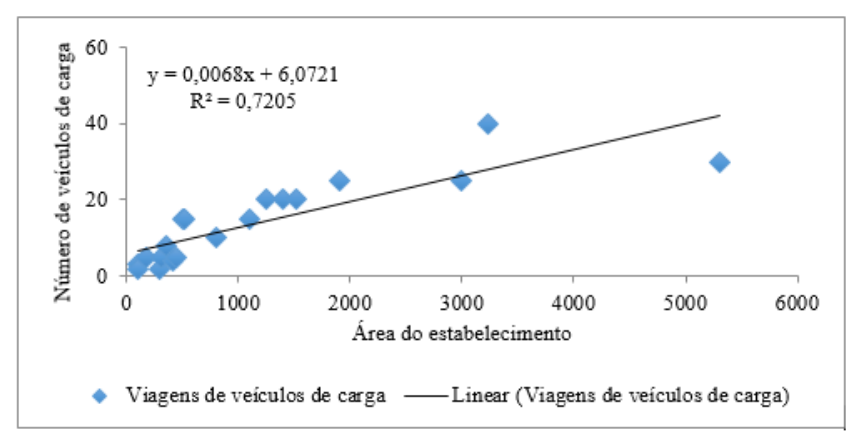

(c) Área e número de viagens de carga para mercados e supermercados

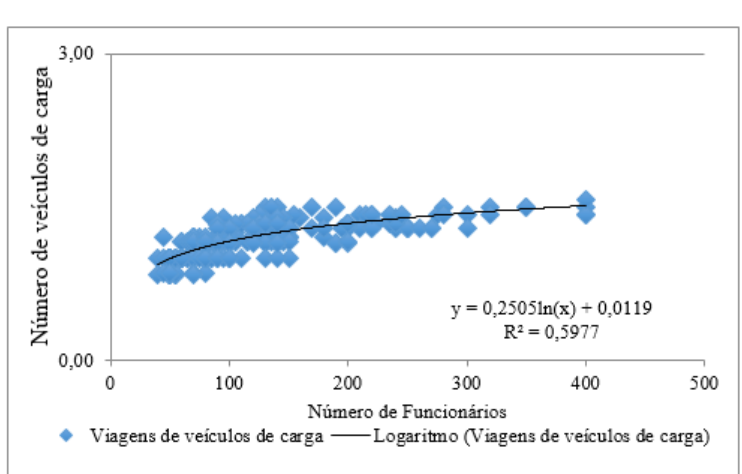

(b) Número de funcionários e número de viagens de carga para bares, lanchonetes e restaurantes

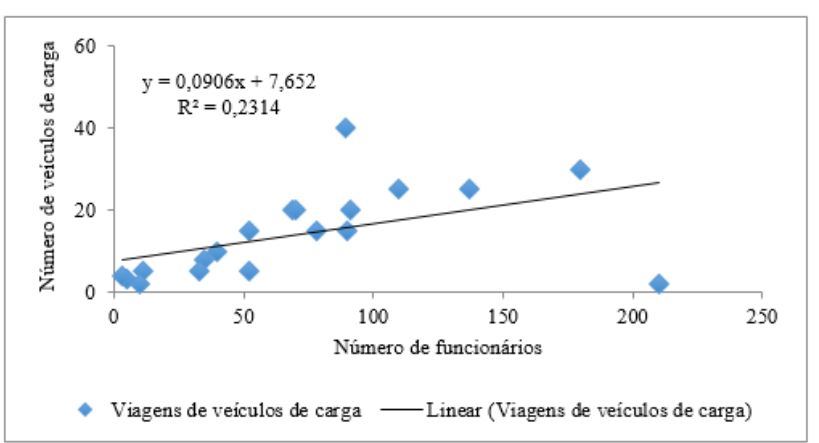

(d) Número de funcionários e número de viagens de carga para mercados e supermercados

Figura 3. Análise da correlação.

\subsection{Etapa 7: Desenvolvimento de modelos de geração/atração de carga}

Os modelos desenvolvidos neste estudo estão apresentados na Tabela 9. Foi utilizada a regressão linear como abordagem metodológica. Para bares e restaurantes, foi considerado, como dimensão temporal, o dia com maior demanda de entregas (terça-feira) e sexta-feira (dia de maior demanda da infraestrutura viária em Belo Horizonte), cujos modelos foram validados estatisticamente $\left(\mathrm{R}^{2} \mathrm{e}\right.$ teste-t) para área de estabelecimento entre 44 e $400 \mathrm{~m}^{2}$ e número de funcionários entre 1 e 21 . Neste estudo, considerou-se como um $\mathrm{R}^{2}$ válido aqueles valores iguais ou superiores a 0,5 e para o teste-t, utilizou-se um nível de confiança de $95 \%$, cujos valores devem ser maiores que 1,96 . Os resultados indicam que:

- Terça-feira

o um metro quadrado de área atrai diariamente 0,0144 viagens de veículos de carga por dia;

○ um funcionário atrai diariamente 0,189 viagens de veículo de carga para o empreendimento.

- Sexta-feira

○ um metro quadrado de área atrai diariamente 0,01152 viagens de veículos de carga por dia;

○ um funcionário atrai diariamente 0,1512 viagens de veículo de carga para o empreendimento.

Para mercados e supermercados foram desenvolvidos modelos para o dia de maior demanda (sexta-feira), sendo que o modelo utilizando a variável independente número de funcionários não foi validado estatisticamente. Para mercados (área entre 100 e $1.900 \mathrm{~m}^{2}$ ), um metro quadrado atrai diariamente 0,0131 viagens de veículos de carga. Para su- permercados (área entre 2.300 e $6.700 \mathrm{~m}^{2}$ ), um metro quadrado atrai diariamente 0,0046 viagens de veículos de carga.

Além destes modelos, na Tabela 10 são apresentados os modelos desenvolvidos para as regionais Centro-Sul, Leste e Oeste para terça-feira e sexta-feira. Tal procedimento foi realizado considerando que as regionais da cidade podem apresentar diferentes padrões de geração de viagens de carga. Os modelos desenvolvidos para bares e restaurantes tiveram as equações por regionais administrativas validadas estatisticamente, contudo com grandes divergências: a regional leste apresenta a maior taxa de geração de viagens e, neste caso, a utilização de taxas de geração de viagens por unidade administrativa podem representar mais fidedignamente a movimentação de mercadorias, destacando a importância da análise espacial para complementar estudos desta natureza.

De maneira similar, os modelos desenvolvidos para o setor de mercado e supermercado, considerando as regionais administrativas de Belo Horizonte, foram considerados estatisticamente válidos, exceto para a variável área do empreendimento nas regionais Barreiro e Noroeste; número de funcionários nas regionais Norte e Noroeste; e número de checkouts na regional Noroeste.

Os resultados dos modelos de geração de viagens para os segmentos analisados foram espacializados, gerados a partir dos modelos que consideram a área do estabelecimento para a sexta-feira. Os mapas temáticos com classes designadas para o número de viagens de carga geradas para os bares, lanchonetes, restaurantes, mercados e supermercados de Belo Horizonte estão apresentados na Figura 4. Os resultados enfatizam que a região Centro-Sul concentra maior atração de viagens de carga devido à maior localização de empreendimentos. 
OLIVEIRA, L.K.; OLIVEIRA, R.L.M.; RAMOS, M.L.A.; EBIAS, D.G.

Tabela 9. Taxa de geração de viagens de veículos de carga

\begin{tabular}{|c|c|c|c|c|c|c|c|}
\hline Setor & $\begin{array}{l}\text { Dimensão } \\
\text { Temporal } \\
\end{array}$ & Variável Dependente & Variável Independente & Modelo & $\mathbf{R}^{2}$ & Teste $\mathbf{t}$ & Domínio \\
\hline \multirow{4}{*}{$\begin{array}{l}\text { Bares, lanchonetes } \\
\text { e restaurantes }\end{array}$} & Terça-feira & \multirow{10}{*}{$\begin{array}{l}\text { Número de viagens de veículos } \\
\text { de carga (NV) }\end{array}$} & \multirow{2}{*}{$\begin{array}{c}\text { Área do Estabelecimento } \\
\text { (A) }\end{array}$} & $\mathrm{NV}=0,0144 \mathrm{~A}$ & 0,82 & 37,88 & $45 \leq \mathrm{A} \leq 400$ \\
\hline & Sexta-feira & & & $\mathrm{NV}=0,01152 \mathrm{~A}$ & 0,82 & 37,88 & $45 \leq \mathrm{A} \leq 400$ \\
\hline & Terça-feira & & \multirow{2}{*}{$\begin{array}{l}\text { Número de Funcionários } \\
\text { (F) }\end{array}$} & $\mathrm{NV}=0,189 \mathrm{~F}$ & 0,68 & 25,54 & $1 \leq \mathrm{F} \leq 21$ \\
\hline & Sexta-feira & & & $\mathrm{NV}=0,1512 \mathrm{~F}$ & 0,68 & 25,54 & $1 \leq \mathrm{F} \leq 21$ \\
\hline \multirow{3}{*}{ Mercados } & \multirow{3}{*}{ Sexta-feira } & & $\begin{array}{l}\text { Área do Estabelecimento } \\
\text { (A) }\end{array}$ & $\mathrm{NV}=0,0131 \mathrm{~A}$ & 0,84 & 10,99 & $100 \leq \mathrm{A} \leq 1.900$ \\
\hline & & & $\begin{array}{l}\text { Número de Funcionários } \\
(\mathrm{F})\end{array}$ & $\mathrm{NV}=0,1867 \mathrm{~F}$ & 0,46 & 2,05 & $3 \leq \mathrm{F} \leq 210$ \\
\hline & & & $\begin{array}{c}\text { Número de } \\
\text { Checkouts (C) }\end{array}$ & $\mathrm{NV}=1,8815 \mathrm{C}$ & 0,56 & 2,05 & $2 \leq \mathrm{C} \leq 15$ \\
\hline \multirow{3}{*}{ Supermercados } & \multirow{3}{*}{ Sexta-feira } & & $\begin{array}{l}\text { Área do Estabelecimento } \\
\text { (A) }\end{array}$ & $\mathrm{NV}=0,0046 \mathrm{~A}$ & 0,74 & 4,88 & $2.300 \leq \mathrm{A} \leq 6.700$ \\
\hline & & & $\begin{array}{l}\text { Número de Funcionários } \\
(\mathrm{F})\end{array}$ & $\mathrm{NV}=0,1669 \mathrm{~F}$ & 0,75 & 2,36 & $3 \leq \mathrm{F} \leq 210$ \\
\hline & & & $\begin{array}{c}\text { Número de } \\
\text { Checkouts (C) }\end{array}$ & $\mathrm{NV}=1,8222 \mathrm{C}$ & 0,58 & 2,04 & $2 \leq \mathrm{C} \leq 15$ \\
\hline
\end{tabular}


Modelo De Geração De Viagens De Carga Em Áreas Urbanas: Um Estudo Para Bares, Restaurantes E Supermercados

Tabela 10. Modelo de geração de viagens de carga por regional administrativa, que destaca as equações não validadas.

\begin{tabular}{|c|c|c|c|c|c|c|c|c|}
\hline Setor & $\begin{array}{l}\text { Dimensão } \\
\text { Temporal }\end{array}$ & Regional & Variável Dependente & Variável Independente & Modelo & $\mathbf{R}^{2}$ & Teste $\mathbf{t}$ & Domínio \\
\hline \multirow{3}{*}{ Bares e Restaurantes } & \multirow{3}{*}{ Sexta-feira } & Centro-Sul & \multirow{3}{*}{ Número de viagens (NV) } & \multirow{3}{*}{$\begin{array}{l}\text { Área do Estabelecimento } \\
\text { (A) }\end{array}$} & $\mathrm{NV}=0,00772$ & 0,823 & 1,970 & \multirow{3}{*}{$45 \leq \mathrm{A} \leq 400$} \\
\hline & & Leste & & & $\mathrm{NV}=0,0101 \mathrm{~A}$ & 0,842 & 2,048 & \\
\hline & & Oeste & & & $\mathrm{NV}=0,00682 \mathrm{~A}$ & 0,805 & 2,034 & \\
\hline \multirow{9}{*}{$\begin{array}{c}\text { Mercados e } \\
\text { Supermercados }\end{array}$} & \multirow{9}{*}{ Sexta-feira } & Barreiro & \multirow{9}{*}{ Número de viagens (NV) } & \multirow{9}{*}{$\begin{array}{l}\text { Área do Estabelecimento } \\
\text { (A) }\end{array}$} & $\mathrm{NV}=0,010 \mathrm{~A}$ & 0,571 & 1,633 & \multirow{9}{*}{$100 \leq \mathrm{A} \leq 6.700$} \\
\hline & & Centro-Sul & & & $\mathrm{NV}=0,004 \mathrm{~A}$ & 0,875 & 5,282 & \\
\hline & & Leste & & & $\mathrm{NV}=0,015 \mathrm{~A}$ & 0,896 & 5,090 & \\
\hline & & Norte & & & $\mathrm{NV}=0,013 \mathrm{~A}$ & 0,899 & 6,666 & \\
\hline & & Nordeste & & & $\mathrm{NV}=0,009 \mathrm{~A}$ & 0,613 & 2,178 & \\
\hline & & Noroeste & & & $\mathrm{NV}=0,003 \mathrm{~A}$ & 0,438 & 1,529 & \\
\hline & & Oeste & & & $\mathrm{NV}=0,004 \mathrm{~A}$ & 0,978 & 9,479 & \\
\hline & & Pampulha & & & $\mathrm{NV}=0,013 \mathrm{~A}$ & 0,998 & 31,560 & \\
\hline & & Venda Nova & & & $\mathrm{NV}=0,016 \mathrm{~A}$ & 0,750 & 3,461 & \\
\hline \multirow{9}{*}{$\begin{array}{c}\text { Mercados e } \\
\text { Supermercados }\end{array}$} & \multirow{9}{*}{ Sexta-feira } & Barreiro & \multirow{9}{*}{ Número de viagens (NV) } & \multirow{9}{*}{$\begin{array}{l}\text { Número de Funcionários } \\
\text { (F) }\end{array}$} & $\mathrm{NV}=0,176 \mathrm{~F}$ & 0,961 & 7,026 & \multirow{9}{*}{$3 \leq \mathrm{F} \leq 210$} \\
\hline & & Centro-Sul & & & $\mathrm{NV}=0,129 \mathrm{~F}$ & 0,913 & 6,464 & \\
\hline & & Leste & & & $\mathrm{NV}=0,192 \mathrm{~F}$ & 0,873 & 4,535 & \\
\hline & & Norte & & & $\mathrm{NV}=0,096 \mathrm{~F}$ & 0,250 & 1,292 & \\
\hline & & Nordeste & & & $\mathrm{NV}=0,267 \mathrm{~F}$ & 0,910 & 5,495 & \\
\hline & & Noroeste & & & $\mathrm{NV}=0,108 \mathrm{~F}$ & 0,517 & 1,793 & \\
\hline & & Oeste & & & $\mathrm{NV}=0,215 \mathrm{~F}$ & 0,873 & 3,714 & \\
\hline & & Pampulha & & & $\mathrm{NV}=0,197 \mathrm{~F}$ & 0,989 & 13,210 & \\
\hline & & Venda Nova & & & $\mathrm{NV}=0,260 \mathrm{~F}$ & 0,956 & 9,301 & \\
\hline \multirow{9}{*}{$\begin{array}{c}\text { Mercados e } \\
\text { Supermercados }\end{array}$} & \multirow{9}{*}{ Sexta-feira } & Barreiro & \multirow{9}{*}{ Número de viagens (NV) } & \multirow{9}{*}{$\begin{array}{l}\text { Número de } \\
\text { Checkouts (C) }\end{array}$} & $\mathrm{NV}=1,316 \mathrm{C}$ & 0,907 & 4,428 & \multirow{9}{*}{$2 \leq \mathrm{C} \leq 15$} \\
\hline & & Centro-Sul & & & $\mathrm{NV}=1,464 \mathrm{C}$ & 0,836 & 4,509 & \\
\hline & & Leste & & & $\mathrm{NV}=1,646 \mathrm{C}$ & 0,919 & 5,850 & \\
\hline & & Norte & & & $\mathrm{NV}=1,697 \mathrm{C}$ & 0,562 & 2,534 & \\
\hline & & Nordeste & & & $\mathrm{NV}=2,146 \mathrm{C}$ & 0,895 & 5,047 & \\
\hline & & Noroeste & & & $\mathrm{NV}=0,756 \mathrm{C}$ & 0,477 & 1,655 & \\
\hline & & Oeste & & & $\mathrm{NV}=1,886 \mathrm{C}$ & 0,845 & 3,304 & \\
\hline & & Pampulha & & & $\mathrm{NV}=1,918 \mathrm{C}$ & 0,997 & 27,577 & \\
\hline & & Venda Nova & & & $\mathrm{NV}=2,428 \mathrm{C}$ & 0,971 & 11,516 & \\
\hline
\end{tabular}




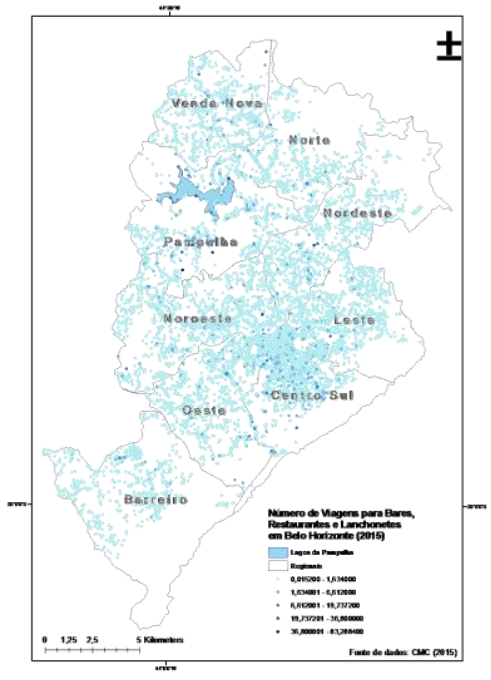

(a) Bares, Restaurantes e Lanchonetes

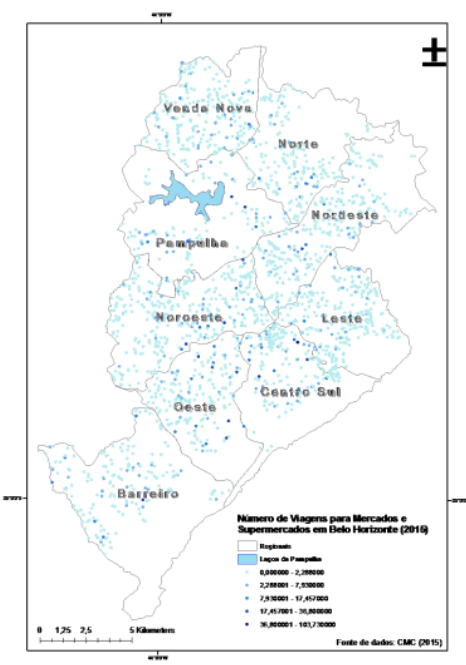

(b) Mercados e Supermercado

Figura 4. Número de Viagens de Carga Geradas em Belo Horizonte.

\subsection{Etapa 8: Verificação do modelo}

Na etapa de verificação do modelo, comparam-se os dados reais obtidos na pesquisa de campo com os dados obtidos através dos modelos desenvolvidos. Considerando as regionais administrativas, para o setor de bares, lanchonetes e restaurantes, o erro médio foi de $-23 \%$, isto é, os valores obtidos com os modelos de geração de viagens são $23 \%$ menores que os valores reais. Para mercados, o erro médio foi de $+6 \%$ e para supermercados, o erro médio foi de $+30 \%$. Estes percentais são similares aos obtidos Kulpa (2014).

\subsection{Etapa 9: Análise de Cluster.}

Considerando a localização dos empreendimentos e a atração de veículos de carga, gerou-se mapas de clusters obtidos para bares, lanchonetes, restaurantes, para mercados e supermercados de Belo Horizonte, apresentados na Figura 5. Para bares, restaurantes e lanchonetes identificamse quatro regionais no município que apresentam concentração de estabelecimentos comerciais com elevado número de viagens em área contígua a estabelecimentos com esta mesma característica (HH), a saber: (i) Centro-Sul; (ii) Nordeste; (iii) Pampulha; (iv) Oeste. A maior concentração destes estabelecimentos na regional Centro-Sul está circunscrita na avenida do Contorno. Na regional Nordeste, há uma aglomeração de estabelecimentos com elevado número de viagens no entorno do Minas Shopping, mas observa-se também a presença significativa de outliers com número de viagens baixo nesta localidade (LH). Na regional Pampulha observa-se uma dispersão espacial dos pontos com elevado número de viagens em áreas com a mesma característica. $\mathrm{Na}$ regional Oeste, esta aglomeração é evidente na área composta pelos bairros Buritis e Estoril. Apenas alguns outliers de estabelecimentos comerciais com elevado número de viagens em áreas de predominância de baixo número de viagens de carga são identificados por meio da técnica aplicada (HL), representados em laranja na Figura 5(a) para bares, restaurantes e lanchonetes.

Para mercados e supermercados destacam-se também áreas com concentração de lojas com elevado número de viagem em áreas com a mesma característica $(\mathrm{HH})$, com destaque para as regionais Barreiro e Centro-Sul. Para os dois conjuntos de dados não foram identificadas aglomerações espaciais caracterizadas pela presença de estabelecimentos comerciais com baixo número de viagens em áreas com predominância de varejo com a mesma característica (LL).

\subsection{Discussões dos Resultados}

Os resultados obtidos neste estudo corroboram com aqueles de Campos et al. (2012) e Comi et al. (2012), em

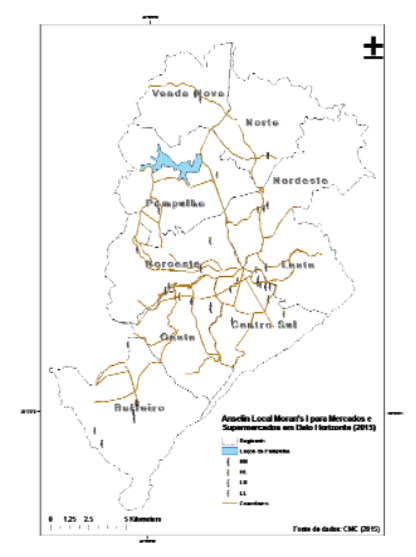

(b) Mercados e Supermercados

(a) Bares, Restaurantes e Lanchonetes

Figura 5. Anselin Local Moran's I para o Número de Viagens de Carga Geradas em Belo Horizonte. 
que a concentração de empreendimentos em uma determinada região implica em um elevado número de veículos de carga realizando entregas, podendo reduzir a mobilidade da região e área do entorno. Proporcionalmente, os segmentos analisados neste estudo (bares, restaurantes e lanchonetes e mercados e supermercados) representam $6 \%$ do total de estabelecimentos comerciais de Belo Horizonte. Tomando-se apenas a área central de Belo Horizonte (parte integrante da regional Centro-Sul), estes segmentos respondem por $42 \%$ das entregas. Além disso, identificou-se que há maior concentração destes estabelecimentos também na regional Centro-Sul, que se caracteriza como uma área do município já bastante comprometida por problemas relacionados à mobilidade.

Em relação às variáveis dependentes e independentes utilizadas neste estudo, a área do estabelecimento pode ser utilizada para explicar a geração de viagens de veículos de carga em Belo Horizonte. A abordagem metodológica utilizando regressão linear mostrou-se adequada para explicar o fenômeno estudado, de maneira análoga aos resultados obtidos em estudos similares no Brasil. Em relação à taxa de viagens de veículos de carga para os empreendimentos analisados, bares, lanchonetes e restaurantes atraem 0,01144 veículos $/ \mathrm{m}^{2} /$ sexta-feira, mercados atraem 0,0131 veícu$\mathrm{los} / \mathrm{m}^{2} / \mathrm{sexta-feira} \mathrm{e} \mathrm{supermercados} \mathrm{atraem} 0,0046$ veícu$10 s / \mathrm{m}^{2} /$ sexta-feira. A validação dos modelos indicou um erro médio inferior a 30\%, quando comparados os resultados dos modelos de geração de viagens de carga com os dados reais.

Comparando os modelos deste estudo com Melo (2002), Silva e Waisman (2007) e Gasparini (2008), podese observar semelhanças e grandes discrepâncias em relação a aplicação dos modelos considerando a área do estabelecimento. Na Figura 6(a) é ilustrada a comparação dos modelos para bares, lanchonetes e restaurantes e permite observar que o modelo de Melo (2002) apresentou resultados similares aos deste estudo, para área do estabelecimento de até $140 \mathrm{~m}^{2}$. Após isto, a taxa de geração de viagens para Belo Horizonte pode ser até $175 \%$ maior que o resultado obtido por Melo (2002). Tal fato pode ser explicado pela validade do domínio da equação de Melo (2002), que não pode ser verificado. Além disso, é possível identificar a divergência do modelo de Silva e Waisman (2007), cujos valores podem ser, em média, $672 \%$ maiores quando comparado aos obtidos neste estudo e, $837 \%$ em relação ao estudo de Melo (2002). Tal fato reforça que resultados das modelagens se restringem à região e ao tipo de atividade/uso do solo estudado, conforme concluído por Silva e Waisman (2007) e Grieco e Portugal (2010).

Na Figura 6 (b) é apresentada a representação gráfica

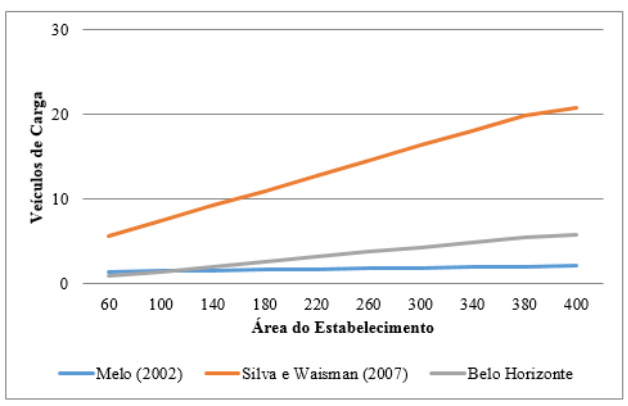

(a) Bares e restaurantes os modelos desenvolvidos para o setor de mercados e supermercados e indica evidente a aderência entre os modelos e a importância de considerar um domínio válido para a equação.

A comparação entre os modelos permite concluir a importância da classificação dos empreendimentos para o estudo da geração de viagens de carga. Para tanto, sugerese a utilização da Classificação Nacional de Atividades Econômicas (CNAE) para padronização de futuros estudos, bem como a classificação dos empreendimentos para representar mais fidedignamente a geração de viagens de carga.

Ainda, as comparações com os modelos desenvolvidos para o mesmo setor no Brasil indicam que é de extrema importância definir o tipo e localização dos empreendimentos além do horizonte do tempo do estudo para validar os modelos e, estes serem instrumentos de planejamento do transporte urbano de mercadorias. A obtenção dos dados utilizando pesquisa de campo mostrou-se eficaz. Contudo ressalta-se a necessidade de que o entrevistado conheça sobre a operação de recebimento de mercadorias.

Além disso, este estudo indicou que não é necessária uma amostra expressiva (como aquela utilizada para bares e restaurantes), mas a amostra necessita ser consistente para validação dos modelos. A inserção da variável geográfica mostrou-se interessante, por permitir identificar, por região, as principais zonas de atração de carga. A utilização de diferentes tipos de ajustes foi explorada neste estudo, contudo apenas modelos que utilizaram o estabelecimento de taxas foram validados.

Outro resultado interessante é a identificação do dia de maior recebimento de mercadoria pelos empreendimentos pesquisados, bem como o período de recebimento. Mercados e supermercados tem mais entregas programadas para sexta-feira. Bares e restaurantes recebem mais entregas na terça-feira e sexta-feira. Em ambos setores, as entregas se concentram no período da manhã.

Além da concentração temporal das atividades relacionadas ao recebimento de cargas, existe a concentração espacial dos estabelecimentos, que contribui para a saturação do sistema viário e, consequentemente, para o agravamento das condições da mobilidade urbana. Assim, foi identificada, tanto para bares e restaurantes como para mercados e supermercados, uma expressiva concentração dos estabelecimentos na porção norte da regional Centro-Sul, área já comprometida pelo excesso de viagens com destino nessa área do município e por caracterizar-se como região de entroncamento dos principais corredores de transporte da cidade. Identificou-se ainda, ao longo destes eixos viários, a ocorrência de suave concentração de mercados e supermercados por todo o município.

Figura 6. Comparação dos modelos nacionais de geração de viagens

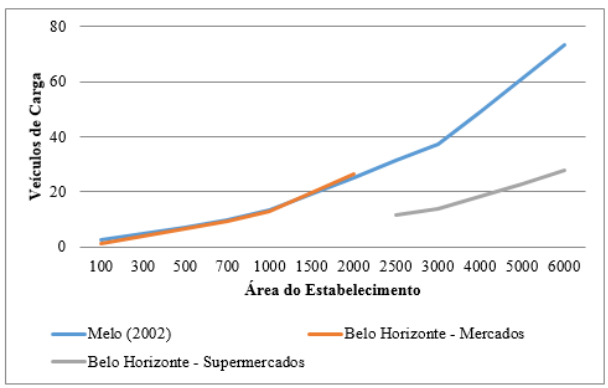

(b) Mercados e supermercados 
Estas vias já apresentam condições de tráfego com elevado nível de complexidade e baixo nível de serviço, por acomodarem os grandes fluxos de deslocamento da população entre as regionais e, em especial, por se caracterizarem como eixos de circulação do transporte coletivo de passageiros. Identificar esta concentração de varejo supermercadista é interessante para subsidiar políticas que visem mitigar o impacto da circulação de veículos de carga nestes corredores, em especial no horário de pico dos fluxos de passageiros.

Desta forma, a utilização da análise espacial para avaliação dos resultados torna-se um instrumento importante por destacar as regiões mais suscetíveis às consequências do transporte urbano de mercadoria, provendo, assim, informações para o desenvolvimento de políticas públicas. A análise de cluster permitiu identificar as regiões com maior concentração de estabelecimentos e entregas, possibilitando definir estratégias específicas para estas áreas, respeitando suas particularidades.

Os resultados obtidos neste estudo reforçam a afirmação de Comi et al. (2012), de que a modelagem da demanda pode ser utilizada em diferentes horizontes de planejamento, sendo:

- horizonte de planejamento estratégico, visto que os resultados identificam o impacto da movimentação de mercadorias na infraestrutura viária, podendo subsidiar a discussão entre os diferentes atores (públicos e privados) para implementação de soluções com investimento em infraestrutura e mudança da tecnologia dos veículos utilizados para a entrega urbana;

- horizonte de planejamento tático, pois os resultados podem auxiliar no planejamento do transporte urbano de mercadorias como definição de políticas para carga e descarga de mercadorias, por exemplo. Exemplo disto ocorre no setor supermercadistas em Belo Horizonte, cu-jos novos empreendimentos devem internalizar área para operações de carga e descarga. Soluções como a entrega noturna também podem ser avaliadas para os setores em estudo;

- programas operacionais, pois os resultados identificam pontos de atenção no fluxo de dois importantes setores econômicos que podem ser objeto de estudo de soluções para minimização das externalidades do transporte urbano de mercadorias.

Finalmente, os resultados podem subsidiar o desenvolvimento da matriz origem-destino de carga, visto que capturam o destino das movimentações de mercadorias, podendo também capturar a origem, conforme proposta de Melo (2002). Pereira e Oliveira (2014) utilizaram dados de Melo (2002) para estimar os fluxos de alimentos e bebidas em Belo Horizonte, obtendo um ajuste de $59 \%$ que pode ser melhorado com os resultados deste estudo. Estas informações são importantes para avaliação da adequabilidade da solução proposta aos problemas de distribuição urbana de mercadorias.

\section{CONSIDERAÇÕES FINAIS}

O desenvolvimento de modelos de geração de viagens de carga pode ser um importante instrumento para conhecer e compreender a movimentação de mercadorias em áreas urbanas e definição de políticas públicas. Contudo, modelos generalistas podem ocultar importantes movimentos de carga na cidade, uma vez que a heterogeneidade espacial é um fenômeno presente e importante na conformação do uso do solo e, portanto, na localização dos estabelecimentos comerciais que geram estes fluxos.

Este artigo apresentou modelos de geração de viagens de carga para bares, restaurantes, mercados e supermercados em Belo Horizonte. O escopo da modelagem considerou o número de veículos de carga atraídos pelo empreendimento no dia pico, utilizando regressão linear para modelar o fenômeno em estudo e considerando a área do empreendimento como variável explicativa. Os resultados foram comparados com estudos similares e observou-se semelhanças (supermercados) e divergências (bares e restaurantes) quando comparados com os modelos nacionais, reforçando a necessidade de modelos locais. A análise espacial permitiu identificar áreas com maior concentração de estabelecimentos e viagens de veículos de carga e podem ser utilizados como subsídio para definição de políticas públicas.

Além disso, este estudo mostrou como a temática ainda é incipiente no Brasil pode ser explorada por pesquisadores para a definição de modelos em diferentes setores econômicos. Como contribuição, este artigo evidenciou a importância da análise espacial para o planejamento do transporte urbano de mercadorias. O uso de técnicas de análise espacial associada à modelagem da demanda permite identificar áreas com maior/menor atração de viagens de carga e pode permitir a proposição de políticas públicas que garantam a mobilidade da mercadoria em Belo Horizonte.

\section{AGRADECIMENTOS}

Os autores agradecem à Prefeitura de Belo Horizonte pela disponibilização dos dados do Cadastro Municipal de Contribuintes e informações complementares cedidas para a realização desta pesquisa. Além disso, os autores agradecem ao Conselho Nacional de Desenvolvimento Científico e Tecnológico $(\mathrm{CNPq})$ pelo auxílio à pesquisa.

\section{REFERÊNCIAS}

Belo Horizonte (2015) Cadastro municipal de contribuintes de tributos. Base de Dados. Prefeitura de Belo Horizonte.

Campos, V. B. G., M. A. D’Agosto, M. A., I. Cruz e C. D. Souza, C. D. (2012) Polos Geradores de Viagens de Carga. In:. Portugal, L. S. (Org.) (2012) Polos Geradores de Viagens Orientados a Qualidade de Vida e Ambiental: Modelos e Taxas de Geração de Viagens. Interciência, Rio de Janeiro.

Campos, V. B. G.; Melo, I. C. B. (2004) Análysis de la demanda de transporte de carga en area urbana bajo el punto de vista de la production y de la atracción de viajes. VI Congreso de Ingenieria del Transporte (CIT 2004). Zaragoza, Espanha.

Comi, A., P. D. Site, F. Fillipi e A. Nuzzolo (2012) Urban Freight Transport Demand Modelling: a State of the Art. European Transport $\backslash$ Trasporti Europei, v.51, n.7. ISSN 18253997. 
Cui, J., J. Dodson e P. V. Hall (2014) Planning for urban freight transport. Transport Reviews, v. 35, n. 5, p. 583-598. doi:10.1080/01441647.2015.1038666

Dutra, N. G. S. (2004) O enfoque de "city logistics" na distribuição urbana de mercadorias. Tese. Universidade Federal de Santa Catarina, Florianópolis.

D’Agosto, M. A., R. A. Rosa, A. F. Ferreira e C. M. Oliveira (2014) Trip generation centers (TGC Cargo) environmental performance evaluation: Libra TECON Terminal case study Rio de Janeiro - Brazil. Anais do XVIII Congresso Panamericano de Engenharia de Trânsito e Transporte e Logística. PANAM, Santander.

Dablanc, L. (2007) Goods transport in large European cities: difficult to organize, difficult to modernize. Transportation Research Part A: Policy and Practice, v. 41, n.3, p. 280-285. doi: http://dx.doi.org/10.1016/j.tra.2006.05.005

Gasparini, A. (2008) Atratividade do transporte de carga para polos geradores de viagem em áreas urbanas. Dissertação. Instituto Militar de Engenharia, Rio de Janeiro.

Gasparini, A., V. B. G. Campos e M. A. D'Agosto (2010) Modelos para estimativa da demanda de viagens de veículos de carga para supermercados e shopping centers. Transportes, v. 18 n. 1, p. 59-65. doi:

http://dx.doi.org/10.14295/transportes.v18i1.383

Gonçalves, F. S., D. S. C. P. S. Lemos, E. C. Kneib e L. S. Portugal (2012) Caracterização dos Polos Geradores de Viagens. In: Portugal, L. S. (Org.). 2012. Polos Geradores de Viagens Orientados a Qualidade de Vida e Ambiental: Modelos e Taxas de Geração de Viagens. Rio de Janeiro: Interciência.

Gonzalez-Felíu, J., F. Semet, F. e J. L. Routhier (2014) Sustainable urban logistics: concepts, methods and information system. Springer, Berlim.

Grieco, E. P. e L. S. Portugal (2010) Taxas de geração de viagens em condomínios residenciais - estudo de caso. Transportes, v. 18, n. 1, p. 87-95. doi:

http://dx.doi.org/10.14295/transportes.v18i1.386

Guimarães, V. A., I. C. Leal Junior, M. A. D'Agosto, A. F. Ferreira e C. M. Oliveira (2014) Desempenho ambiental de polos geradores de viagens de carga. Journal of Transport Literature, v. 8, n. 3, p. 250-269. doi: http://dx.org/10.1590/S223810312014000300011

Holguín-Veras, J., M. Jaller, L. Destro, X. Ban, C. Lawson e H. Levinson (2011) Freight generation, freight trip generation and perils of using constant trip rates. Transportation Research Record: Journal of the Transportation Research Record, n. 2224, p. 68-81. doi: http://dx.doi.org/10.3141/2224-09

Holguín-Veras, J., M. Jaller, I. Sanchez-Diaz, J. Wojtowicz, S. Campbell, H. Levinson, C. Lawson, E. L. Powers e L. Tavasszy (2012) Freight Trip Generation and Land Use. NCFRP REPORT 19: National cooperative freight research program.

Transportation Research Boarding, Washington, D.C.

IBGE (2015) Cidades@. Instituto Brasileiro de Geografia e Estatística.

ITE (2008) Trip Generation: An ITE Informational Report. Institute of Transportation Engineers, Washington.
Kulpa, T. (2014) Freight truck trip generation modeling at regional level. Procedia - Social and Behavioral Sciences, v. 111, p. 197-202. doi: http://dx.doi.org/10.1016/j.sbspro.2014.01.052

Marra, C. (1999) Caracterização de demanda de movimentações urbanas de cargas. Dissertação. Universidade Estadual de Campinas, Campinas.

Melo, I. C. B. (2002) Avaliação de demanda por transporte de carga em áreas urbanas. Dissertação. Instituto Militar de Engenharia, Rio de Janeiro.

Oliveira, C. M., A. F. Ferreira, M. A. D’Agosto, I. C. Leal Junior e V. A. Guimarães (2014) Aprimoramento do desempenho ambiental de polos geradores de viagens (PGV carga): estudo de caso do terminal Sepetiba Tecon. Journal of Transport Literature, v. 8 , n. 3, p. 270-289. doi: http://dx.doi.org/10.1590/S223810312014000300011

Oliveira, L. K. (2014) Diagnóstico das vagas de carga e descarga para a distribuição urbana de mercadorias: um estudo de caso em Belo Horizonte. Journal of Transport Literature, v. 8, n. 1, p. 178-209. doi: http://dx.doi.org/10.1590/S223810312014000100009

Pereira, L. S. F. e L. K. Oliveira (2014) Metodologia para estimativa de fluxos de carga a partir de dados secundários: uma aplicação em Belo Horizonte. Journal of Transport Literature, v. 8, n. 4, p. 279-315. doi: http://dx.doi.org/10.1590/22381031.jtl.v8n4a11

Portugal, L. S. (2012) Polos Geradores de Viagens de Carga. Polos Geradores de Viagens Orientados a Qualidade de Vida e Ambiental: Modelos e Taxas de Geração de Viagens. Interciência, Rio de Janeiro.

Prata, B. A., L. K. Oliveira, N. G. S. Dutra e W. A. Pereira Neto (2012) Logística Urbana: fundamentos e aplicações. Editora CRV, Curitiba.

Rodrigue, J. P. (2013) The geography of transport system. Routledge, New York.

Rogerson, P. A. (2012) Métodos Estatísticos para Geografia: Um Guia para o Estudante. Bookman, Porto Alegre.

Silva, M. R. e J. Waisman (2007) Cargas urbanas: estudo exploratório sobre a geração de viagens de caminhões em bares e restaurantes. Anais do $16^{\circ}$ Congresso Brasileiro de Transporte e Trânsito. ANTP, Maceió.

Souza, C. D. R., S. D. Silva e M. A. D’Agosto (2010) Modelos de geração de viagens para pólos geradores de viagens de carga. Transportes, v. 18, n. 1, 46-57. doi: http://dx.doi.org/10.14295/transportes.v18i.396

Taniguchi, E., R. Thompson, T. Yamada e R. V. Duin (2001) City Logistics: Network Modelling and Intelligent Transport Systems. Pergamon, Oxford. 